\title{
The effect of use complementary and alternative medication combined conventional medicine in chronic pain patients
}

Shu-pen Hsu., Pao-chin Lai., Yi-ting Lu. Shin Kong Wu HO-SU Memorial Hospital. Taipei, Taiwan. ROC.

\section{Background}

In recent years, there has been a remarkable increase in interest and use of complementary and alternative medicine (CAM). Conventional medicine is the mainstream of global doctor's advice, it still does not help many patients. More and more patients with chronic Pain seek out alternative or complementary treatment. It is crucial for the health care provider to identify the factors related to the patients' choices of treatment. Patients with chronic pain commonly experience depression, sleep disturbance, fatigue, and decreased overall physical and mental functioning.

\section{Purpose}

1. The situation of use complementary and alternative medication combined conventional medicine in chronic pain patients.

2.The effect of use complementary and alternative medication combined conventional medicine in chronic pain patients.

\section{Methods}

\section{Setting and sample}

This cross-sectional study was based on a convenience sample of outpatients in Taiwan. During the period from January 2018 to May 2018, the case was conveniently collected Adult patients were patients who have been diagnosed with chronic pain.

\section{Instrument}

A 22-item descriptive questionnaire was used to collect the data including demographic, clinical, and use of CAM sections.

To establish the validity of this instrument, content validity was measured by the judgments of a panel of five experts and high degree of agreement was found among these panel experts.

\section{Results}

\section{Demographic characteristics in the table 1}

A total of 68 patients were invited but 4 declined. In total, 28 female and 36 male patients completed the survey. The mean age of this sample group was 62.5 years $(\mathrm{SD}=12.5)$. The mean of the time since pain for this sample group was 32.3 months $(\mathrm{SD}=$ 31.9)with a range from less than 3 months to 134 months

Table 1 Demographic characteristics of Sample $(N=65)$

\begin{tabular}{|l|c|c|}
\hline Characteristic & Frequency (n) & Percent \\
\hline Gender \\
\hline Male & & \\
\hline Female & 36 & 43.7 \\
\hline Age (years) & 28 & 56.3 \\
\hline$=<40$ & & \\
\hline $41-50$ & 2 & 3.1 \\
\hline $51-60$ & 10 & 15.6 \\
\hline $61-70$ & 20 & 25 \\
\hline$>70$ & 16 & 31.3 \\
\hline Cause of pain & & 25 \\
\hline Disease & 43 & \\
\hline accident & 13 & 67.2 \\
\hline unknow & 8 & 20.3 \\
\hline Time since Pain & & 12.5 \\
\hline$<=12$ Months & 29 & 45.3 \\
\hline$>12-24$ Months & 7 & 10.9 \\
\hline$>24-36$ Months & 6 & 9.4 \\
\hline$>36-48$ Months & 3 & 4.7 \\
\hline$>48-60$ Months & 1 & 1.6 \\
\hline$>60$ Months & 18 & 28.1 \\
\hline CAM used & & \\
\hline Yes & 52 & 81.2 \\
\hline No & 12 & 18.8 \\
\hline
\end{tabular}

\section{Characteristic of CAM use in the table 2}

The most common CAM therapies used currently were Dietary supplements $(15.86 \%, \mathrm{~N}=23)$, followed by Massage $(13.1 \%, \mathrm{~N}=19)$, and acupuncture $12.41 \%, \mathrm{~N}=18)$. And then vitamin supplements $(11.72 \%, \mathrm{~N}=17)$.

The mean score of patients' perceived effectiveness with cupping use was 4.25 (SD $=2.0$ ), followed by chiropractic mean was $4.0(\mathrm{SD}=2.83)$ and Foot massage was $4.0(\mathrm{SD}=2.55)$.

Table 2 Details the frequency and effect of CAM use $(\mathrm{N}=145)$

\begin{tabular}{lcccc} 
Characteristic & $\begin{array}{c}\text { Frequency } \\
\text { (n) }\end{array}$ & $\begin{array}{c}\text { Percent } \\
(\%)\end{array}$ & $\begin{array}{c}\text { *Perceived effectiveness } \\
\text { mean }\end{array}$ & SD \\
\hline Chinese medicine & 11 & 7.59 & 2.45 & 1.92 \\
Dietary supplements & 23 & 15.86 & 1.09 & 1.54 \\
vitamin supplements & 17 & 11.72 & 1.18 & 2.0 \\
Massage & 19 & 13.10 & 3.74 & 2.33 \\
Foot massage & 5 & 3.45 & 4.0 & 2.55 \\
manipulation in & 11 & 7.59 & 3.18 & 2.44 \\
medicine & & & & \\
chiropractic & 6 & 4.14 & 4.0 & 2.83 \\
scraping & 7 & 4.83 & 3.56 & 2.30 \\
cupping & 8 & 5.52 & 4.25 & 2.00 \\
acupuncture & 18 & 12.41 & 3.22 & 2.56 \\
Tai Chi & 3 & 2.07 & 1.67 & 2.89 \\
Gi Gong & 2 & 1.38 & 2.50 & 2.12 \\
Buddhist scriptures & 10 & 6.90 & 3.1 & 3.1 \\
reading the Bible & 1 & 0.69 & 3.0 & 0 \\
Fortune-telling & 2 & 1.38 & 1 & 1 \\
Ask God & 2 & 1.38 & 0.5 & 0.71
\end{tabular}

*The degree of perceived effectiveness with CAM used were each measured by using a 10-point scale. Higher scores indicate greater degree of effectiveness .

\section{Conclusions}

Additionally, the health care system in Taiwan, Massage and acupuncture is available treatment provided in some hospitals and clinics by the qualified doctors who have been trained.

It is important that health professionals should initiate communication regarding CAM with patients to ensure that patients are using CAM appropriately and safely. Nurses are in a key position to not only provide knowledge and information about CAM but also to develop guidelines about CAM use for chronic pain patients. 